\title{
Primary meningeal B lymphoma presenting as a subacute ascending polyradiculoneuropathy
}

Jean Julien, Claude Vital, Janine Rivel, Antoine de Mascarel, Alain Lagueny, Xavier Ferrer, Béatrice Vergier

\begin{abstract}
A subacute ascending polyradiculoneuropathy was the main feature of a primary meningeal $B$ lymphoma in two patients. Tumour cells appeared in the CSF eight and six months respectively after the onset of the disease. Treatment by intrathecal methotrexate resulted in transient improvement.
\end{abstract}

Primary lymphomas of the CNS are uncommon, comprising around $0.8 \%$ of all lymphomas. Meningeal involvement is found in $24 \%$ of these primary lymphomas. ${ }^{1}$ Meningeal involvement may cause headache with papilloedema ${ }^{2}$ multiple involvement of cranial nerves, ${ }^{3}$ or radicular or plexal syndrome. ${ }^{1}$ Our two cases had an ascending polyradiculoneuropathy with unusual features: subacute course, severe pain in all four limbs, asymmetrical motor impairment, amyotrophy and sphincter disturbances.

\section{Case reports}

Case 1

In August 1986, a 70 year old retired man was investigated for paraesthesiae of both feet. Neurological examination detected distal hypoaesthesia for touch and pinprick with a sock distribution, and bilateral loss of ankle reflexes. The patient had had a history of noninsulin-dependent diabetes mellitus over the previous ten years managed by diet. In October the patient's condition deteriorated with an onset of motor disorders in the lower limbs in a distal distribution with occasional fasciculations. Cell count in the CSF revealed 30 lymphocytes, and 8 polymorphonuclear cells $/ \mu \mathrm{l}$ and a protein content of $40 \mathrm{mg} /$ $100 \mathrm{ml}$. No abnormal cells were found after CSF centrifuge preparation. Cultures were negative. Electrophysiological studies were indicative of an axonal neuropathy in the lower limbs without evidence of any conduction block. Routine laboratory tests and chest radiograph were normal, while tests for Lyme disease and HIV were negative.

In December there was further deterioration with pain in the lower limbs, increased weakness and walking difficulties. The CSF contained 64 lymphocytes and 16 polymorphonuclear cells, but no abnormal cells, and a protein content of $60 \mathrm{mg} / 100 \mathrm{ml}$. In February 1987, there was a marked deterioration in general status, with a loss of $12 \mathrm{~kg}$ over six months. Paraesthesiae had appeared in the right hand with paresis and muscle wasting. In March, there was a right facial weakness, dysphonia and dysphagia. CSF contained 90 lymphocytes $/ \mu$ l with no abnormal cells. CSF protein content had risen to $110 \mathrm{mg} / 100 \mathrm{ml}$ with a normal electrophoretic pattern (gammaglobulin 10.2\%). EMG detected severe axonal neuropathy in all four limbs with diffuse fibrillation potentials.

A biopsy of the superficial peroneal nerve was carried out. There were a few ovoids on semi-thin sections. The number of myelinated fibres was $7400 / \mathrm{mm}^{2}$ with a bimodal distribution. At ultrastructural examination some fibres showed features of acute axonal degeneration. Other fibres were almost totally destroyed and there was only a Schwann cell membrane surrounding a macrophagic histiocyte. Scattered histiocytes were observed in the endoneurium.

In April 1987, there was an increased motor deficit, extension of the cranial nerve palsies and onset of a confusional state. The CSF contained 42 lymphocytes and 38 immature lymphoblastic cells. Bone marrow biopsy was normal. There was no lymphadenopathy or splenomegaly. Abdominal and brain CT scans were normal. Treatment by intrathecal methotrexate together with cerebral and spinal radiotherapy resulted in improvement over the first three weeks with disappearance of the oculomotor disorders, pain reduction and improvement of upper limb deficit. The neurological state subsequently deteriorated with altered consciousness, and the patient died on 20 July 1987 after an 11 month course.

At necropsy, no pulmonary invasion or mediastinal involvement were observed. Spleen size was normal, and no abnormalities were found in the liver, kidneys, pancreas or digestive tract. No abnormalities in brain or spinal sections were detected on macroscopic examination.

Microscopic examination with immunopathological procedures using a peroxidaseanti-peroxidase method was performed on brain, spinal cord and nerve root fragments. Deparaffinised, rehydrated sections were analysed with the following antibodies: MB2 (Eurodiagnostic) and L26 (Dako) recognise B cells and UCHL 1 (Dako) T cells. Spinal fragments and nerve roots at different levels were infiltrated by tumour cells. Other infiltrates forming small perivascular cuffs were visible inside the roots (fig 1). These tumour infiltrates were composed of rounded elements, some of which displayed plasma- 


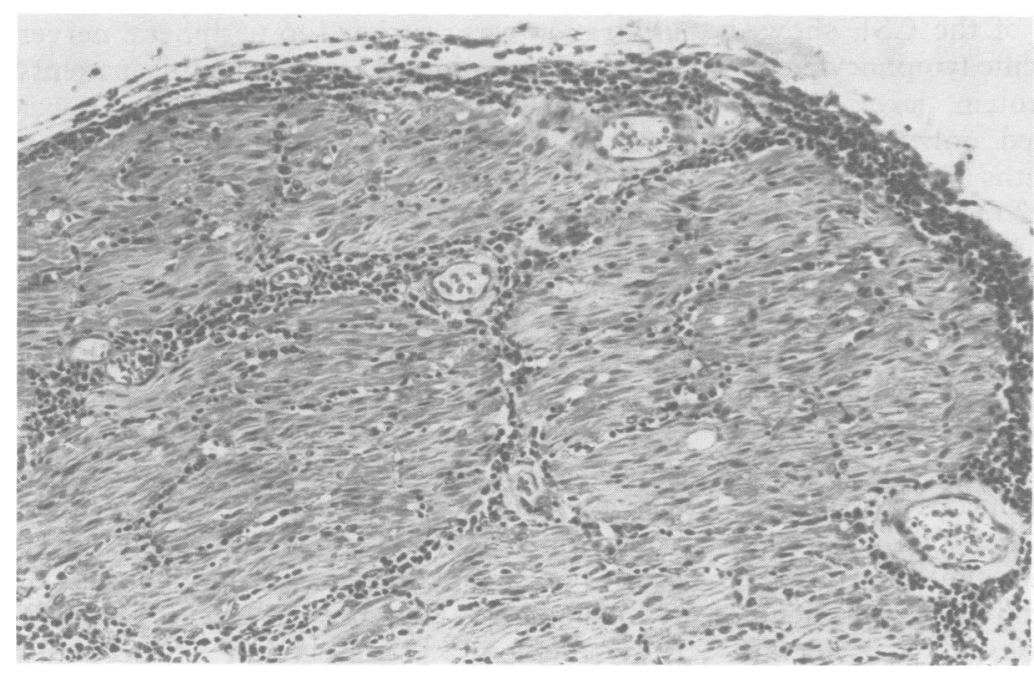

Figure 1 The periphery of this lumbar root is infiltrated by lymphomatous cells. Haematoxylin eosin $\times 220$.

cytic features, although others were composed of much larger cells. The nuclei of the large cells were of irregular shape and size and contained large nucleoli. Mitoses were visible. The tumour cells were marked by MB2, L26 and were negative for UCHL 1 , thus indicating a B-cell origin. Anterior horn cells occasionally showed signs of an onset of central chromatolysis. Some cranial nerves were widely infiltrated with extension into the peduncular parenchyma. In the cerebral hemispheres, lymphomatous infiltrates were visible in the leptomeninges in the lower regions of the temporal lobes and in the insula, with some cells forming perivascular cuffs in the neighbouring cortex. No leptomeningeal or parenchymal infiltration was observed in other regions of the cerebral hemispheres.

\section{Case 2}

A 67 year old woman had been treated by diet for 12 years for a noninsulin-dependent diabetes mellitus. In July 1988, there appeared paraesthesiae in the lower limbs followed 15 days later by motor deficits in a distal distribution with nocturnal painful episodes. Reflexes were absent and hypoaesthesia with a sock distribution was found in all modalities. Upper limbs and cranial nerves were normal. The CSF contained 43 lymphocytes. Abnormal cells were not detected and protein content was $90 \mathrm{mg} / 100 \mathrm{ml}$. Cell cultures were negative.

Figure 2 CSF centrifuge preparation demonstrating lymphomatous cells. Several mitoses are visible. GIEMSA $\times 300$.
MRI of brain and bone scintigraphy were normal. EMG indicated an asymmetric axonal neuropathy with fibrillation potentials at rest in the tibialis anterior and the quadriceps. Motor nerve conduction velocities in the left peroneal nerve and sensory nerve conduction velocities in the right sural nerve were normal. White blood cell counts, serum electrophoresis and immunoelectrophoresis were normal. Increasing sensory deficits in the lower limbs induced ataxia and severe walking difficulties. CSF examination on 25 August showed a cell content of 39 lymphocytes/ $\mu$ l with no abnormal cells, and a protein content of $120 \mathrm{mg} / 100 \mathrm{ml}$ with a rise in gammaglobulins $(15 \cdot 2 \%)$ at electrophoresis. Tests for Lyme disease and HIV were negative.

At the beginning of October there was a weakness of the right hand and urinary incontinence. In November, motor impairment worsened in the legs. Sensory disturbances increased in the upper limbs, with bilateral muscle wasting of the hands. Swallowing disturbances and diplopia appeared in December. CSF was cloudy with 250 cells $/ \mu$ l; the cells were large with voluminous irregular nuclei and discrete basophilic cytoplasm. Tumour cells showed appropriate staining with MB2 and L26, but no staining with UCHL 1 by immunohistochemistry (fig 2), thus suggesting a B-cell population. General examination was normal without lymph node enlargement. Liver and spleen were normal. Chest radiograph, abdominal CT scan and gastric fibroscopy were normal. On bone marrow smears there was no lymphocytic infiltration, and normal cell proportions.

On semi-thin sections the number of myelinated fibres was $8584 / \mathrm{mm}^{2}$ with a bimodal distribution. At ultrastructural examination some scattered myelinated fibres exhibited various stages of axonal degeneration. There was no interstitial infiltration by lymphomatous cells. Intrathecal administration of methotrexate (10 mg every five days) led to improvement for three weeks with regression of the diplopia, and the swallowing disorder. Pain also improved but with a rebound effect. The patient died in February 1989 after a nine month course. Necropsy was not permitted.

\section{Discussion}

Necropsy findings in case 1 and the negative results of general investigations in case 2 indicated primary meningeal involvement. Cytological investigations of CSF in both cases showed the presence of large cells with irregularly-shaped voluminous nuclei containing large nucleoli. Ultrastructural examination of peripheral nerve biopsies in both cases demonstrated axonal lesions with no lymphomatous infiltrates in the peripheral nerve. In our cases as in most other primary CNS lymphomas, infiltrates encompassed B cells.

In both these cases, the clinical picture was a subacute ascending polyradiculoneuropathy with sensory and motor deficits in the lower limbs, subsequently extending to the upper limbs and cranial nerves. Over a period of 
several months, analysis of the CSF showed only a moderate non-specific lymphocyte content with increased protein levels. Lymphomatous cells appeared only late in the course, eight and six months after the onset of symptoms in cases 1 and 2 respectively. When diagnosis was achieved by CSF centrifuge preparation, the patients were treated by intrathecal methotrexate which was associated with radiotherapy in case 1 . There was some improvement in both cases, although the improvement was of short duration (three to four weeks) with a further progressive deterioration despite continued treatment.

There have been six previous reports of meningeal lymphomas with clinical manifestations of subacute ascending polyradiculoneuropathy. ${ }^{4-9}$ Including our two cases, meningeal involvement was primary in four cases, ${ }^{57}$ and secondary to a systemic lymphoma in the other four. ${ }^{4689}$ However, in these latter cases, there was no or little clinical evidence of lymphoma. These reports concerned three men and five women aged 33 to 75 (mean 60.1) years. As in our cases severe pain was a prominent feature, ${ }^{5-8}$ generally with nocturnal deterioration. Pain was the first sign in three cases. ${ }^{578}$ Sensorimotor neuropathy was asymmetric in all cases but one, ${ }^{4}$ and like ours was associated with marked wasting. ${ }^{5-7}$ Occasional fasciculations ${ }^{56}$ and abolition of deep tendon reflexes have also been noted. Multiple cranial nerve paresis has also been described resulting in dysphagia, dysphonia, facial weakness or facial diplegia, ${ }^{46}$ but it is notable that in all these eight cases oculomotor disturbances were present. Sphincters were involved in our cases and three others. $^{4-6}$ A confusional state arose generally late in the course. The CSF was normal in two cases. ${ }^{45}$ There was a moderate pleocytosis with lymphocytes and an elevated protein content in our cases and three others. ${ }^{6-8}$ Lymphomatous cells were observed at the first lumbar puncture in one. ${ }^{9}$ The total duration of the neurological illness ranged from 11 days ${ }^{8}$ to 22 months ${ }^{6}$ with a mean of seven months. Intrathecal injection of methotrexate proved to be either without effect or of transient efficacy.

Necropsy was performed in seven of these cases. Gross examination of the brain and spinal cord revealed mild lesions, except in the case of Garcin et $\mathrm{l}^{5}$ where a marked meningeal thickening was observed. Histological examination showed diffuse infiltration of the subarachnoid space over the cerebral hemisphere, the brain-stem, the spinal cord and intradural nerve roots. In four cases ${ }^{569}$ a lymphomatous infiltration was also observed in peripheral nerves.

In meningeal lymphoma, peripheral nerve involvement may be secondary to the compression of anterior or posterior roots by lymphomatous infiltrates leading to Wallerian degeneration (our cases and two others ${ }^{4}$ ). Moreover, the meningeal and radicular involvement can be accompanied by infiltration of nerves with penetration of lymphomatous cells into the perineurium and endoneurium, thus producing myelin axonal breakdown. ${ }^{589}$ In some observations where lymphomatous infiltration was restricted to peripheral nerves with no meningeal involvement, patients presented with a neuropathy of the lower limbs, ${ }^{1011}$ sometimes with an ascending course. ${ }^{11}$ In those cases where cell type was specified, it was a $\mathrm{T}$-cell lymphoma. ${ }^{10-12}$

In systemic lymphoma, at least six peripheral neurological syndromes can either precede or reveal the disease: an axonal neuropathy with evidence of multiple conduction blocks related to the presence of circulating antibodies, ${ }^{13}$ demyelinating sensori motor peripheral neuropathy associated with paraprotein, ${ }^{14}$ subacute motor neuronopathy, ${ }^{15}$ a paraesthetic sensory neuropathy with localised pain as a result of neoplastic angioendotheliosis. ${ }^{1617}$ Guillain-Barré syndrome with active demyelination, ${ }^{18}$ sensorimotor neuropathy with severe demyelination and moderate axonal degeneration have been reported as a remote effect of malignant lymphoma. ${ }^{19} \mathrm{~A}$ classification for peripheral neuropathy associated with lymphoma has recently been proposed. ${ }^{20}$

Patients with meningeal lymphoma usually die within weeks or months after the onset of symptoms. In some cases, however, death occurs within a few days ${ }^{21}$ and in others there may be a relapsing and remitting course for several years. ${ }^{22}$

The origin of lymphomatous cells in the CNS and PNS is unclear. Non-neoplastic lymphocytes may be attracted into the CNS by a viral process such as Epstein-Barr virus. ${ }^{23} \mathrm{~A}$ clone of inflammatory cells could then be transformed into neoplastic cells. Such a hypothesis could explain in our cases the presence of inflammatory cells in the CSF at an early stage of the disease and the delayed appearance of tumour cells in the CSF.

1 Hochberg FH, Miller DC. Primary central nervous system lymphoma. J Neurosurg 1988;68:835-53.

2 Griffin JN, Thompson RW, Mitchinson MJ, de Kiewiet JC, Welland FH. Lymphomatous leptomeningitis. Amer $J$ Welland FH. Lymp

3 Teoh R, Barnard RO, Gautier-Smith PC. Polyneuritis cranialis as a presentation of malignant lymphoma. $J$ Neurol Sci 1980;48:399-412.

4 Allison RS, Gordon DS. Reticulosis of the nervous system simulating acute infective polyneuritis. The Lancet 1955;ii:120-2.

5 Garcin R, Gruner J, Tinel G. Sur un cas de neurolymphomatose humaine. Etude anatomo-clinique. Rev Neurol (Paris) 1953;88:81-92.

6 Guberman A, Rosenbaum H, Braciale T, Schlaepfer WW Human neurolymphomatosis. J Neurol Sci 1978;36:1-12.

7 Jellinger $\mathrm{K}$, Kotbauer $\mathrm{P}$, Weiss $\mathrm{R}$, Sunder-Plassmann $\mathbf{E}$. Primary malignant lymphoma of the CNS and polyneuropathy in a patient with necrotizing vasculitis trea
with immunosuppression. $J$ Neurol 1979;220:259-68.

with immunosuppression. $J$ Neurol $1979 ; 220: 259-68$.
Kohut H. Unusual involvement of the nervous system in Kohut $H$. Unusual involvement of the nervous system in
generalized lymphoblastoma. J Neurol Ment Dis 1946; 103:9-20.

9 Moore RY, Oda Y. Malignant lymphoma with diffuse involvement of the peripheral nervous system. Neurology 1962;12:186-92.

10 Zuber M, Gherardi R, Imbert M, Gaulard P, Kuentz M, Poirier JJ. Peripheral neuropathy with distal nerve infiltration revealing a diffuse pleiomorphic malignant lymphoma. J Neurol 1988;235:61-2.

11 Gherardi R, Gaulard Ph, Prost C, Rocha D, Imbert M, André C, Rochant H, Farcet JP. T-cell lymphoma revealed by a peripheral neuropathy. Cancer 1986;58:2710-6.

12 Kuroda $Y$, Nakata $H$, Kakigi $R$, Oda $K$, Shibasaki $H$, Nakashiro $\mathrm{H}$. Human neurolymphomatosis by adult $\mathrm{T}$ cell leukemia. Neurology 1989;39:144-6.

13 Latov N. Peripheral neuropathy and IgM monoclona gammopathy. In: Aarli JA, Behan WMH, Behan PO, eds. Clinical neuroimmunology Oxford: Blackwell Scientific Publications, 1987:214-24. 
14 Ince PG, Shaw PJ, Fawcett PRW, Bates D. Demyelinating neuropathy due to primary IgM Kappa B cell lymphoma of peripheral nerve. Neurology 1987,37:1231-5.

15 Schold SC, Cho ES, Somasundaram M, Posner JB. Subacute motor neuronopathy: a remote effect of lymphoma. Ann Neurol 1979;5:271-87.

16 Beal MF, Fisher CM. Neoplastic angioendotheliosis. $J$ Neurol Sci 1982;53:359-75.

17 Vital C, Heraud A, Vital A, Coquet M, Julien J, Maupetit J. Acute mononeuropathy with angiotrophic lymphoma. Acta Neuropathol (Berlin) 1989;Suppl VII:249-51.

18 Brechenmacher C, Vital C, Laurentjoye L, Castaing Y. Ultrastructural study of peripheral nerve in Guillain Barre Syndrome. Presence of mononuclear cells in axons. Acto Neuropathol (Berlin) 1981; Suppl VII:249-51.
19 Blanchard MB. Peripheral neuropathy (non-invasive) associated with lymphoma. Ann Intern Med 1962;56:
$774-8$.

20 Vital C, Vital A, Julien J, et al. Peripheral neuropathies and lymphoma without monoclonal gammopathy: a new classification. J Neurol 1990;237:117-85.

21 Haberland C, Cipriani M, Kucuk O, Sarpel G, Ezdinli EZ Ro JO. Fulminant leukemic polyradiculoneuropathy in case of B-cell prolymphocytic leukemia. Cancer 1987; 60:1454-8.

22 Borit A, Altrocchi PH. Recurrent polyneuropathy and neurolymphomatosis. Arch Neurol 1971;24:40-9.

23 Weiss LM, Movahed LA. In situ demonstration of EpsteinBarr viral genomes in viral-associated B-cell lymphoproliferations. Am J Pathol 1989;134:651-9. 